\title{
Aquatic pollution increases the relative success of invasive species
}

\author{
Jeffrey A. Crooks • Andrew L. Chang • \\ Gregory M. Ruiz
}

Received: 24 October 2009/Accepted: 17 June 2010/Published online: 11 July 2010

(C) The Author(s) 2010. This article is published with open access at Springerlink.com

\begin{abstract}
Although individual ecosystems vary greatly in the degree to which they have been invaded by exotic species, it has remained difficult to isolate mechanisms influencing invader success. One largely anecdotal observation is that polluted or degraded areas will accumulate more invaders than less-impacted sites. However, the role of abiotic factors alone in influencing invisibility has been difficult to isolate, often because the supply of potential invaders is confounded with conditions thought to increase vulnerability to invasion. Here, we conducted a field experiment to test how the assemblages of exotic versus native marine invertebrates changed during community assembly under different exposure levels of a common pollutant, copper. The experiment was conducted by deploying fouling panels in a Randomized Block Design in San Francisco Bay. Panels were periodically removed, placed into buckets with differing copper
\end{abstract}

J. A. Crooks ( $₫)$

Tijuana River National Estuarine Research Reserve, 301 Caspian Way, Imperial Beach, CA 91932, USA e-mail: jcrooks@trnerr.org

J. A. Crooks - A. L. Chang - G. M. Ruiz Smithsonian Environmental Research Center, 647 Contees Wharf Road, Edgewater, MD 21037, USA

A. L. Chang

Department of Environmental Science and Policy, One Shields Avenue, University of California, Davis, CA 95616, USA concentrations, and returned to the field after 3 days. This design allowed propagule availability to the plates to be statistically independent of short-term copper exposure. The results demonstrate that copper caused significant differences in community structure. Average native species richness was significantly affected by copper exposure, but average exotic richness was not. The total native species pool within treatments exhibited a greater than $40 \%$ decline within increasing copper, while the exotic species pool did not change significantly. These results confirm that anthropogenic alteration of abiotic factors influences invader success, indicating that management strategies to reduce invader impacts should include both efforts to improve environmental conditions as well as reduce invader supply.

Keywords Invasions - Invasibility · Habitat $\cdot$ Propagule pressure $\cdot$ Fouling · Diversity

\section{Introduction}

Determining the factors that make ecosystems vulnerable to biological invasions has long been a principal challenge in ecology (Elton 1958; Lonsdale 1999; Ruiz et al. 2000). Considerable attention has recently been paid to biotic factors influencing invasibility, such as the diversity of resident native species (Levine and D'Antonio 1999; Lonsdale 1999; 
Shea and Chesson 2002; Knight and Reich 2005; Olyarnik et al. 2009) and prevalence of natural enemies (Torchin et al. 2003). There has been a relative lack of emphasis on abiotic determinants of invasibility (Menke and Holway 2006), despite the observation that such factors underlie many observed cases of biotic resistance (or lack thereof) to invasion (e.g., Byers 2002; Davies et al. 2005; Von Holle 2005).

Abiotic factors often considered to influence invasibility include pollution and physical disturbance (Hobbs and Huenneke 1992; D'Antonio et al. 1999; Sax and Brown 2000; Crooks and Suarez 2006; Lohrer et al. 2008). Roadsides typically have more exotic species than intact vegetation away from roads (Tyser and Worley 1992; Gelbard and Belnap 2003), and in tropical forests, plant invasions are positively correlated with anthropogenic disturbance (Fine 2002). Along rural to urban gradients, examination of species such as plants and birds reveal shifts from natives to exotics as urbanization increases (Kowarik 1995; Blair 1996), and within urbanized lands, exotics are often found in association with the urban core and smaller, more degraded natural remnants (Suarez et al. 1998; Crooks et al. 2004). In marine systems, exotics are usually more associated with urbanized bays and estuaries than the less-impacted open coast (Carlton 1979; Preisler et al. 2009).

The central problem in assessing ecosystem vulnerability to invasions, however, is that the number of non-native species in a system cannot be used as a measure of invasibility (Lonsdale 1999; Chytrý et al. 2008; Olyarnik et al. 2009). Besides the bias imposed by incomplete sampling efforts (Ruiz et al. 2000), the number of established exotics is a function of both the supply of potential invaders, or propagule pressure, as well as susceptibility to invasion determined by both abiotic and biotic factors (Lonsdale 1999; Lockwood et al. 2005). Are roadsides and harbors more invaded because they have environmental conditions which favor invaders, or are they invaded because of differences in invader supply? Roadsides have passing vehicles to spread invasive plants, and many of the transport mechanisms for marine systems (e.g., ballast water and ship fouling) tend to be strongly associated with bays and estuaries. This confounding of propagule pressure and invasibility emphasizes the need to control for availability of invaders when assessing invasion patterns
(Lonsdale 1999; Clark and Johnston 2005; Colautti et al. 2006).

Three broad approaches can be used to try and disentangle propagule pressure from environmental factors influencing the relative success of exotic species (Johnston et al. 2009). One approach involves assessing propagule supply itself, either directly or by use of some proxy. For example, records from intentional introductions (Veltman et al. 1996), numbers of visitors to parks (Lonsdale 1999), and vector activity (Levine and D'Antonio 2003) have been used to correlate propagule pressure with number of established exotics. The second approach is to experimentally add known quantities of propagules to systems experiencing differing environmental conditions (e.g., Burke and Grime 1996; Foster et al. 2002; Woitke and Dietz 2002). In terrestrial systems, soil disturbance and removal of biomass increased the number and cover of alien plants sown onto plots (Petryna et al. 2002), and addition of known quantities of seeds demonstrated that the invasive plants responded to a combination of physical disturbance and nutrient addition (Hobbs and Atkins 1988). In the marine environment, Clark and Johnston (2005) found that physical disturbance mediated resource availability and thereby invasion success (establishment) of bryozoan larvae injected into experimental enclosures.

The third approach to account for propagule pressure is to employ experimental designs that use natural colonization to replicate plots under differing, experimentally-imposed environmental conditions (Colautti et al. 2006). This approach has the advantage of not having to manipulate supply of propagules, potentially allowing the examination of large complements of species under more natural recruitment regimes. However, it also makes it relatively difficult to actually quantify propagule pressure, given expected spatio-temporal variability in a potentially diverse and fluctuating pool of colonizers. The variable supply of individuals across experimental units also can make it more difficult to detect treatment effects, and experiments designed to avoid confounding treatment with location effects also should be utilized (Colautti et al. 2006). Piola and Johnston (2006a, b) used such an approach in marine fouling communities, and demonstrated that the timing and duration of copper exposure increased the diversity and dominance of exotics in fouling communities. 
In order to further explore the role of abiotic factors in affecting invasibility, and to specifically isolate the degree to which the magnitude of environmental degradation affects exotic and native species success, we conducted an experiment with the heavily-invaded fouling communities in San Francisco Bay, California, USA. Fouling communities are ideal for such experiments as they develop rapidly, are relatively easy to manipulate, and have high species richness in small areas. They also have previously been used to gain insight into invasibility (Stachowicz et al. 2002; Piola and Johnston 2006a, b; Piola and Johnston 2008). In our experiment, we determined how pulsed exposure to different concentrations of the pollutant, copper, affected invader success during community assembly. Copper represents a common metal pollutant in estuarine systems, coming from diverse sources such as anti-fouling paints, wood preservatives, industrial waste, sewage discharge, and urban runoff (Piola and Johnston 2008). This experiment was conducted under a natural recruitment regime, where the entire suite of larval invertebrates in the water column was available to establish on all experimental colonization panels, which were deployed in a block design. This allowed the key variable of propagule pressure to be statistically independent of copper exposure, thus allowing an unbiased assessment of responses of exotic and native species to increasing pollution levels during community assembly.

\section{Methods}

\section{Experimental design}

The experiment was conducted with fouling plates off a seawall at the Romberg Tiburon Center, San Francisco State University (Tiburon, San Francisco Bay, California, USA). We deployed thirty fouling panels in five blocks along approximately $100 \mathrm{~m}$ of seawall, and periodically (every 4-6 weeks) retrieved the panels and either placed them in buckets with varying levels of a copper sulfate solution (treatments), or returned them to the field (control). The duration of copper exposure was $72 \mathrm{~h}$, after which the plates were returned to their original locations off the seawall. The plates were 14- $\times 14-\mathrm{cm}$ PVC panels that were mounted on bricks using cable ties and suspended panel-side down at a depth of approximately $1 \mathrm{~m}$ below Mean Lower Low Water (Fig. 1).

A Randomized Complete Block (RCB) design was used, with five blocks of five copper addition treatments: zero copper $(0 \mu \mathrm{g} / \mathrm{l}), 15,50,100$, and $200 \mu \mathrm{g} / \mathrm{l}$,
Fig. 1 One experimental block (of five), showing PVC plates attached to bricks and deployed in San Francisco Bay. Treatment and control plates were randomly located within each of the five blocks (i.e., in a Randomized Complete Block design). Treatment plates were removed from the water and placed in buckets of differing copper concentrations for $72 \mathrm{~h}$, while control plates were removed and immediately returned to the water

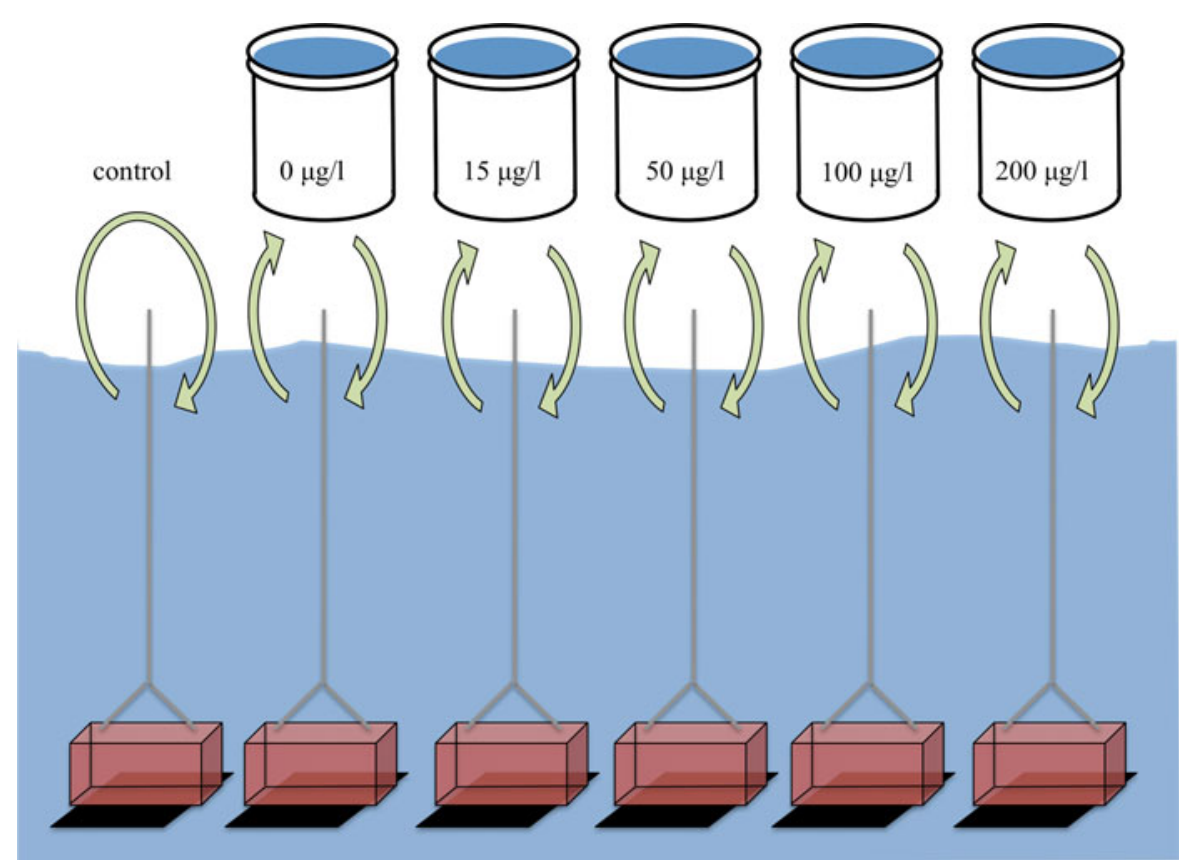


plus the control which was retrieved and returned to the water without placement in buckets (Fig. 1). In general, copper concentrations were chosen to reflect increasing exposure to a potential stressor, and not necessarily the effects of copper at specific concentrations per se. However, copper concentrations up to approximately $50 \mu \mathrm{g} / \mathrm{l}$ can be found in polluted marine environments (Piola and Johnston 2009), while the two higher levels represent more extreme conditions (e.g., comparable to those used to control nuisance invertebrates in marine aquaria). To achieve desired concentrations, a copper sulfate solution was added to seawater so that the concentration in the bucket would initially equal the desired concentration (plus any trace amounts that might be present in the ambient seawater). Because copper concentrations decreased with time, additional copper sulfate solution was added after $36 \mathrm{~h}$ in an amount equal to half the concentration of the original added copper sulfate solution. The buckets were placed in a bath of flowing seawater (to help control temperature) and were aerated with airstones. Five copper exposures were completed in this manner over the course of 24 weeks.

Upon final retrieval of plates we compiled species presence/absence data by identifying all morphotaxa present on each panel. Because of difficulties identifying barnacles using external morphology, we dissected 10 haphazardly chosen barnacles per plate for more detailed taxonomic assessment. Species were assigned to the categories of exotic, native, or cryptogenic (of unknown origin) based on published literature and established criteria (Carlton 1979; Cohen and Carlton 1995). The cryptogenic category accounts for species whose status is uncertain-they are neither clearly exotic nor native (Carlton 1996). For our analyses, we also included as cryptogenic higher-order taxa for which species-level identifications were not possible.

In order to further assess changes in community structure in response to the experimental treatments, we used point counts to generate percent covers of taxa on plates. For this analysis, a grid of 100 points was placed over each plate, and the taxa present at each point were identified to lowest taxonomic level possible. For several taxa, it was not possible to consistently identify organisms at the points to the species level due to the small sizes of some individuals (lacking key characters) and difficult taxonomic assessments (e.g., the barnacles). Thus, higher taxonomic groups were used where necessary, and these data were used to investigate broader patterns (e.g., total space occupancy, percent cover of dominant taxonomic groups, and community similarities) rather than test responses of exotics and natives.

Statistical analysis

Differences in average richness of exotic and natives species per plate were assessed using a Randomized Complete Block ANOVA. Examination of differences among individual treatments was conducted using Fisher's Least Significant Difference. Analyses were conducted on log-transformed data to examine multiplicative rather than additive effects (Mead 1988). Means and standard errors are presented in original units, and thus were back-transformed for presentation (resulting in asymmetric standard errors which are presented as ranges in tabular form). Species prevalence within treatments was assessed by examining the number of replicate plates on which a given species was found, and differences between representation on the highest and lowest copper plates were tested using Fisher's Exact Test. Responses of the total number of exotic and native species across replicate plates with treatments (i.e., pooled species richness) were assessed using linear regression.

These analyses considered only species classified as exotics and natives, and cryptogenics were not included (Table 1). In order to address the possible effects of this categorization, however, additional analyses were done using a more liberal assignment of species to the exotic category. These demonstrated patterns that were very similar to those found with original classifications (Appendix A).

Percent cover data generated from point counts were assessed using both univariate and multivariate analyses. Differences in percent cover of taxa across experimental treatments were tested using ANOVA on arcsine-square root transformed data (which were back-transformed for presentation). Analyses of community similarity, using average percent covers in the different treatments, were done by performing non-metric Multi-Dimensional Scaling (MDS) and an Analysis of Similarities (ANOSIM), using PRIMER software (Clarke and Gorley 2001; Clarke and Warwick 2001). This was followed by an analysis of taxa contributing most to observed differences, using Species Contribution to Similarity (SIMPER). 
Table 1 Taxonomic list, including assignments as exotic, native, or cryptogenic, and representation in the different experimental treatments and control

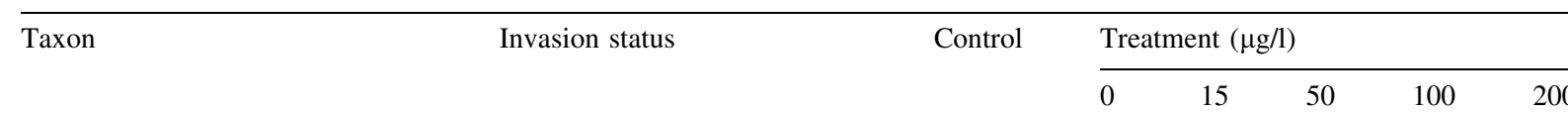

Sponges

Haliclona sp.

Hydroids

Clytia sp.

Ectopleura crocea

Garveia annulata

Garveia franciscana

Opercularella sp.

Obelia bidentata

Scyphozoa

Unidentified scyphistoma

Polychaetes

Pseudochitinopoma occidentalis

Serpulid sp. A

Serpulid sp. B

Bivalves

Mytilus spp.

Ostrea conchaphila

Barnacles

Balanus crenatus

Balanus improvisus

Kamptozoa

Unidentified kamptozoan

Bryozoans

Alcyonidium mamillatum

Alcyonidium cf. polyoum

Anguinella palmata

Aspidelectra cf. melolontha

Bowerbankia aggregata

Bugula pacifica

Bugula cf. longirostrata

Caulibugula ciliata

Celleporella hyalina

Conopeum osburni

Conopeum reticulum

Crisia occidentalis

Cryptosula pallasiana

Electra monostachys

Fenestruloides cf. eopacifica

Filicrisia franciscana

Parasmittina californica

Schizoporella pseudoerrata

Schizoporella variabilis
Exotic

Cryptogenic

Exotic

Cryptogenic

Exotic

Cryptogenic

Cryptogenic (Probable exotic)

Cryptogenic

Native

Cryptogenic

Cryptogenic

Cryptogenic

Native

Native

Exotic

Cryptogenic

Cryptogenic

Cryptogenic (Probable exotic)

Exotic

Cryptogenic (Probable exotic)

Cryptogenic (Probable exotic)

Native

Native

Native

Native

Native

Cryptogenic (Probable exotic)

Native

Exotic

Exotic

Native

Native

Native

Exotic

Exotic

$+$

+
+
+

$+$

$+$

$+$

$+$

$+$

$+$

$+$

$+$

$+$

$+$

$+$

$+$

$+$

$+$

$+$

$+$

$+$

$+$

$+$

$+$

$+$

$+$

$+$

$+$

$+$

$+$

$+$

$+$

(50)

$+$


Table 1 continued

\begin{tabular}{|c|c|c|c|c|c|c|c|}
\hline \multirow[t]{2}{*}{ Taxon } & \multirow[t]{2}{*}{ Invasion status } & \multirow[t]{2}{*}{ Control } & \multicolumn{5}{|c|}{ Treatment $(\mu \mathrm{g} / \mathrm{l})$} \\
\hline & & & 0 & 15 & 50 & 100 & 200 \\
\hline Scrupocellaria diegensis & Native & + & + & + & + & + & \\
\hline Smittoidea prolifica & Native & + & + & + & + & + & + \\
\hline Tegella cf. circumclathrata & Native & & + & & & & \\
\hline Tricellaria occidentalis & Native & & + & + & + & + & \\
\hline Watersipora cf. subtorquata & Exotic & + & + & + & & + & \\
\hline \multicolumn{8}{|l|}{ Tunicates } \\
\hline Ascidia zara & Exotic & & + & + & + & & \\
\hline Ciona intestinalis & Exotic & & & & & + & \\
\hline Ciona savignyi & Exotic & & + & + & + & + & + \\
\hline Styela clava & Exotic & + & + & + & + & + & + \\
\hline
\end{tabular}

Also noted are the 5 cryptogenic species which represent probable exotics, and were considered as such in a re-analysis to test to robustness of the patterns given a different categorization (see Appendix 1)

\section{Results}

In all, 44 species (or higher taxa) were found on the plates (Table 1). Sixteen species were considered to be natives, and fourteen exotic. Fourteen were not assigned to either category and were considered cryptogenic (see also Appendix A). Bryozoans were the higher-order taxa most commonly found on the plates, consisting of over half the total species. Six of these were considered exotic. Other taxa on the plates included polychaetous annelids, tunicates, hydroids, the scyphistoma stage of jellyfish, barnacles, kamptozoans, mussels, oysters, and sponges.

Native vs. exotic species richness on plates

The total pools of native and exotic species responded differently to the experimental treatments (Fig. 2). Every native species found in the entire experiment (sixteen total) was found at least once within the zero copper treatment, when pooling across all replicates. With increasing copper, there was a decline of over $40 \%$ in total (pooled) species richness on plates, which is statistically significant $\left(F_{1,3}=32.9, P=0.01\right)$. Over $90 \%$ of the variation in native species response could be explained by increasing copper $\left(R^{2}=0.916\right)$. Total exotic species pools demonstrated a different pattern (Fig. 2), and the slopes of the regression lines for native and exotic species with increasing copper were significantly different $\left(F_{1,6}=19.5, P=0.005\right)$. Exotic species

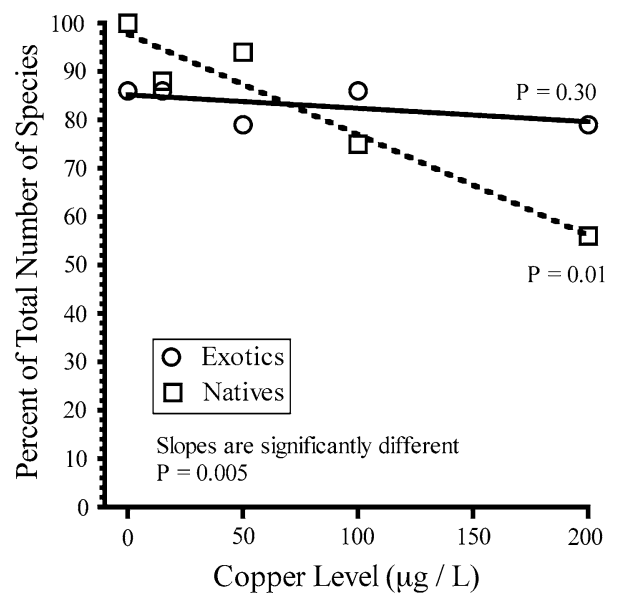

Fig. 2 Pooled species richnesses of natives and exotics found across all replicate plates in the copper treatments (total $n=5$ ), expressed as the percentage of the total number of species found for each group in the entire experiment. Also presented are significance of the regression lines, as well as the significance of the difference between the two lines

richness did not change significantly with increasing copper $\left(F_{1,3}=1.6, P=0.297\right)$, and copper levels only explained $35 \%$ of the variation $\left(R^{2}=0.346\right)$. Unlike native species, there was some turnover of species with increasing copper (Fig. 2). Two species found at the zero copper concentration dropped out with increasing copper (the bryozoan Watersipora $\mathrm{cf}$. subtorquata and the tunicate Ascidia zara), while two species (the tunicate Ciona intestinalis and the hydroid Garveia franciscana) were only found at higher copper levels. 
Comparing presence of species on replicate plates in the highest copper treatment to that in the zero copper treatment also revealed differences between exotic and native species representation. Ten native species (out of the sixteen total) were found on more replicate zero copper than high copper plates. Only one native, the bryozoan Celleporella hyalina, was found on more replicate plates in the high than the zero copper treatment. For exotic species however, six of the fourteen species were found more frequently on the high copper plates. These included the bryozoans Cryptosula pallasiana and Electra monostachys; the tunicate Ciona savignyi; the hydroids Ectopleura crocea and Garveia franciscana; and the barnacle Balanus improvisus. This difference in response between exotics and natives in high copper vs. zero copper plates is significantly different (Fisher's Exact Test, $P=0.03$ ).

Average exotic and native species richness per plate also showed differences in responses. For native species, there was a significant treatment effect, while there was no significant treatment effect for exotics (Table 2). Average native species richness declined with increasing copper within the bucket treatments, with numbers in the 15,100 , and $200 \mu \mathrm{g} / \mathrm{l}$ being significantly lower than those in the zero copper treatment (Table 2). For exotics, only the highest

Table 2 (A) Average numbers of native and exotic species on the treatment and control plates. Analyses were done on logtransformed data, and data presented are back-transformed averages as well as lower and upper limits representing one SE copper treatment had significantly lower average species richness than the zero copper treatment (Table 2). Block effects were significant for both exotics and natives. Also, the placement of panels in buckets did not diminish species richness on plates, and species richness actually tended to be lower in the control treatment (which was returned to the field rather than placed in buckets) than in the zero copper addition bucket treatment (Table 2).

\section{Percent cover of major taxa}

The cover patterns on the plates, as determined by point counts, again demonstrated changing communities with increased copper. Overall, total percent cover was relatively high (approximately $75 \%$ ) on all but the highest copper treatment, which had approximately $25 \%$ lower coverage of than that in the other treatments (Fig. 3a). The similarity of the communities in the treatments, examined with MDS ordination of average percent covers in a treatment (Fig. 4), reflected general patterns observed with assessments of species richness. There were significant differences in communities (ANOSIM Rho $=0.181, P=0.045$ ), with the highest copper treatment being most distinct. The community in the control treatment was more

about the mean. (B) Randomized Complete Block ANOVA tables for exotic and native species responses to copper (see text for more detail)

\begin{tabular}{|c|c|c|c|c|c|c|}
\hline \multirow[t]{2}{*}{ (A) Treatment } & \multicolumn{3}{|c|}{ Native species } & \multicolumn{3}{|c|}{ Exotic species } \\
\hline & \multicolumn{3}{|c|}{ Mean (SE range) } & \multicolumn{3}{|c|}{ Mean (SE range) } \\
\hline Control & \multicolumn{3}{|c|}{$8.7(8.1-9.3)^{*}$} & \multicolumn{3}{|c|}{$4.7(4.0-5.6)$} \\
\hline $0 \mu g / l$ & \multicolumn{3}{|c|}{$10.1(9.5-10.8)$} & \multicolumn{3}{|c|}{$5.4(4.9-6.1)$} \\
\hline $15 \mu \mathrm{g} / 1$ & \multicolumn{3}{|c|}{$9.0(8.0-10.1)^{*}$} & \multicolumn{3}{|c|}{$5.6(4.7-6.7)$} \\
\hline $50 \mu \mathrm{g} / 1$ & \multicolumn{3}{|c|}{$9.2(8.0-10.7)$} & \multicolumn{3}{|c|}{$4.7(4.0-5.6)$} \\
\hline $100 \mu \mathrm{g} / 1$ & \multicolumn{3}{|c|}{$7.3(6.3-8.4)^{*}$} & \multicolumn{3}{|c|}{$5.1(4.2-6.1)$} \\
\hline \multirow[t]{2}{*}{$200 \mu \mathrm{g} / 1$} & \multicolumn{3}{|c|}{$6.0(5.2-6.8)^{*}$} & \multicolumn{3}{|c|}{$3.6(2.4-5.3)^{*}$} \\
\hline & \multicolumn{3}{|c|}{ Native species } & \multicolumn{3}{|c|}{ Exotic species } \\
\hline (B) Source of variation & $\mathrm{df}$ & $F$ & $P$-value & df & $F$ & $P$-value \\
\hline Treatment & 5 & 4.43 & 0.007 & 5 & 1.13 & 0.379 \\
\hline Block & 4 & 4.91 & 0.006 & 4 & 7.33 & 0.001 \\
\hline Error & 20 & & & 20 & & \\
\hline
\end{tabular}

* Statistically different from zero copper treatment, using Fisher's LSD 
Fig. 3 Average percent cover of all macrofauna and the five most abundant taxa in the experimental treatments and control (con), as well as ANOVA results for the treatment effect. Statistics were performed on arcsinesquare root transformed data, which were backtransformed for presentation

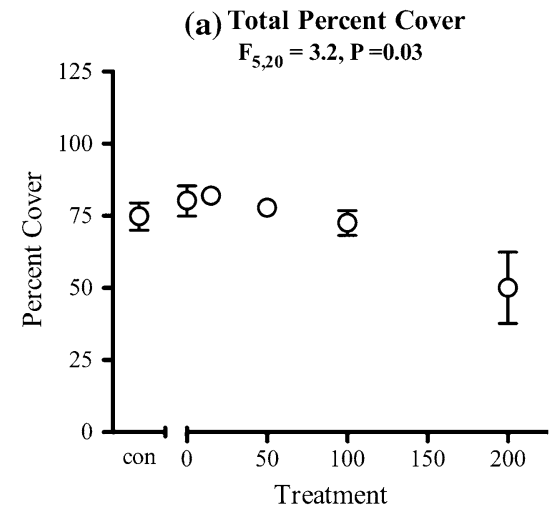

(c) Conopeum \& Electra spp.

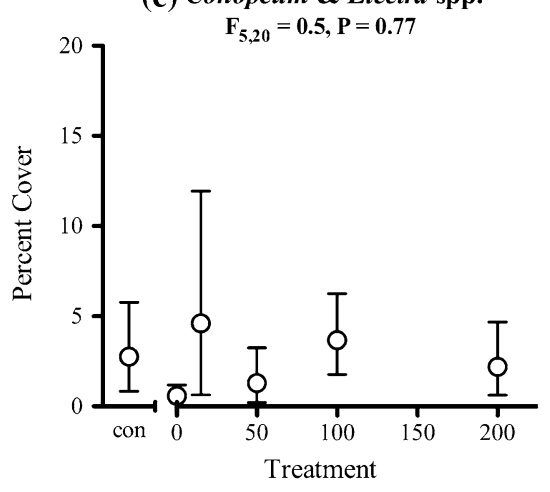

(e) Bowerbankia aggregata

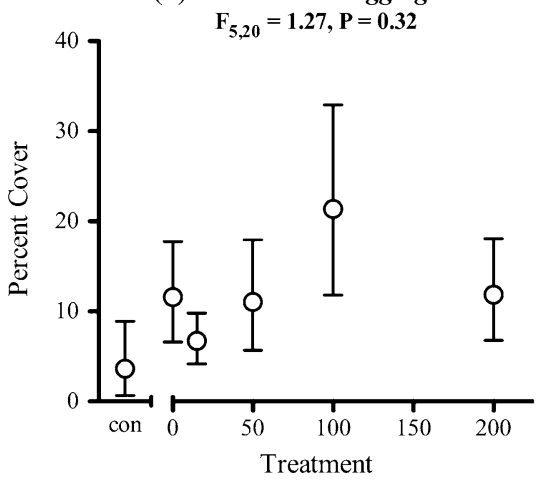

(b) Balanus spp.

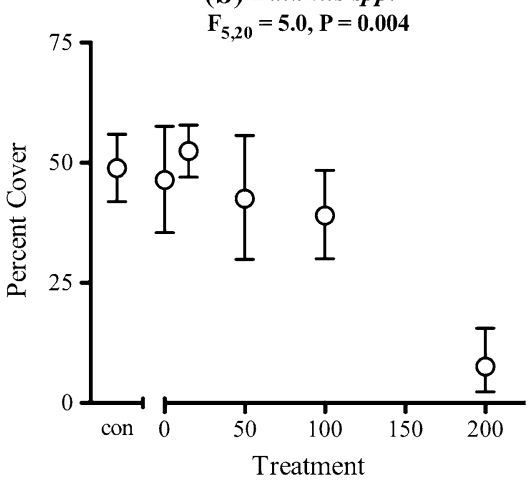

(d) Schizoporella spp.

$\mathrm{F}_{5,20}=\mathbf{2 . 4}, \mathrm{P}=\mathbf{0 . 0 7}$

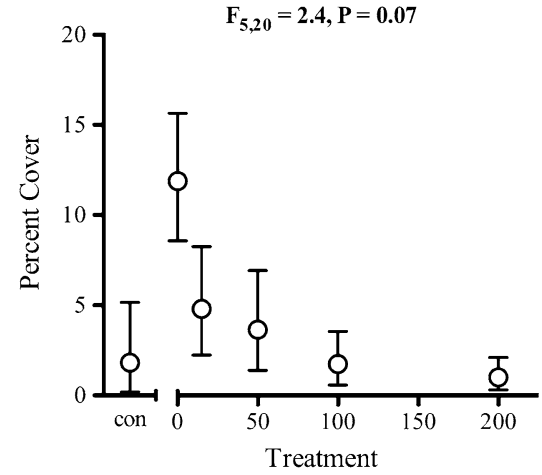

(f) Alcyonidium spp.

$\mathrm{F}_{5,20}=0.03, P=0.99$

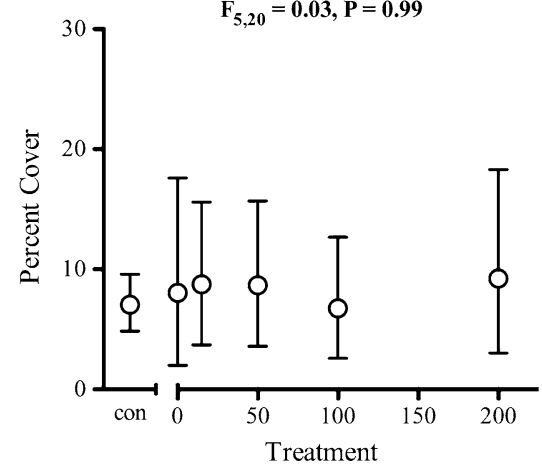

similar to some of the intermediate copper treatments than it was to the zero copper treatment.

The taxa that contributed most to community differences between the zero copper treatment and those with copper additions, as assessed with SIMPER (Table 3), were barnacles (Balanus spp.) and four bryozoans (Alcyonidium spp., Bowerbankia aggregata, Schizoporella spp. and the combined Conopeum/Electra spp.). Overall, barnacles were the dominant space occupiers on the plates, although their abundance decreased significantly with increasing copper (Fig. 3b). The encrusting bryozoan Schizporella spp. also showed a trend of decreasing abundance with increasing copper (except for relatively low abundances in the control plates) (Fig. 3d).

\section{Discussion}

This experiment demonstrates that community structure, including patterns of exotic and native richness, differ with exposure to increasing concentrations of a 


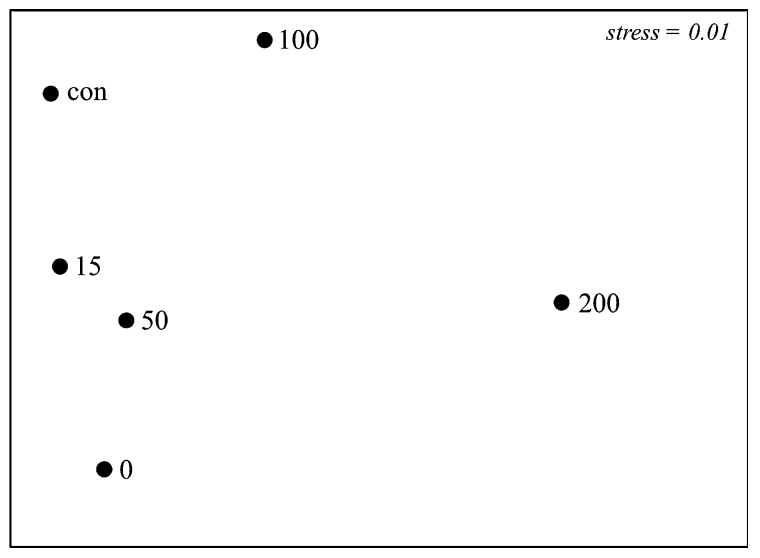

Fig. 4 Results of MDS analysis, showing similarities of communities based on average percent covers in the experimental treatments and control (con). (see text for more details)

common aquatic pollutant, copper. Within the range tested, the richness of exotic species on plates was largely not affected by copper levels, while native species richness was. Our results are consistent with the hypothesis that the prevalence of exotics in areas such as roadsides and urbanized bays results from more than just increased availability of invaders in such areas.

This experiment utilized a design allowing the full complement of species available in the ambient environment to recruit to panels, thus permitting the assessment of a diverse assemblage of native and exotics species. The significant block effects often observed in this study indicate a strong effect of plate location, likely reflecting spatial differences in recruitment and growth (and also emphasizing the importance of partitioning as much observed variance in the data as possible to evaluate treatment effects). Also, the imposition of the experimental treatment, the short-term (less than $10 \%$ of the total time) placement in buckets, resulted in communities that differed from those left in the field (Table 2; Fig. 4). Somewhat surprisingly, however, those communities in the control treatment (returned to the water without placement in buckets) more closely resembled communities with intermediate levels of copper exposure, rather than some more diverse community. This is perhaps related to bucket-induced stress (or disturbance sensu lato) causing a relaxation of predation or competitive pressure, allowing for more species to be present. This could be a manifestation of a sort of intermediate disturbance effect (Grime 1973; Connell 1978), albeit one where there are two distinct types of disturbance-placement in buckets and exposure to copper.

A variety of potential mechanisms underlie the differing responses of exotics and natives to abiotic factors, including both species-specific and community-level responses (D’Antonio et al. 1999). Specieslevel responses, including both lethal and sub-lethal effects (e.g., physiological, metabolic, and behavioral), are likely important at several stages in the invasion process. These are often best examined in more-isolated field or laboratory experiments. For example, work on invasive bryozoans, including species found in this study (Bugula neritina and Watersipora subtorquata), have demonstrated substantial tolerances to copper (Floerl et al. 2004, Piola and Johnston 2006a, b). This relative success of invaders with increasing loads of pollutants such as copper likely reflects a "weeding out" process that occurs during anthropogenic invasions, where the rigors of transport tends to select for species able to tolerate unfavorable environmental conditions. For example, exotic species now in San Francisco Bay have survived conditions during long-distance transport, such as those encountered in metal ballast tanks
Table 3 Results of SIMPER analyses, comparing copper addition treatments to the zero copper treatment. The average dissimilarities, as well as taxa contributing most to these dissimilarities, are presented. (see text for more details)

\begin{tabular}{lrrrr}
\hline & \multicolumn{4}{c}{ Copper addition treatment $(\mu \mathrm{g} / \mathrm{l})$} \\
\cline { 2 - 5 } & \multicolumn{1}{c}{15} & 50 & 100 & 200 \\
\hline Average dissimilarity compared to zero copper treatment & 40.8 & 44.9 & 44.9 & 58.7 \\
Contributions of taxa & & & & \\
Balanus spp. & 7.4 & 9.4 & 8.8 & 17.8 \\
Conopeum \& Electra spp. & 10.2 & 5.0 & 6.6 & 5.6 \\
Schizoporella spp. & 8.4 & 9.3 & 11.0 & 10.8 \\
Bowerbankia aggregata & 8.7 & 9.4 & 11.1 & 7.8 \\
Alcyonidium spp. & 12.3 & 10.9 & 12.0 & 10.7 \\
\hline
\end{tabular}


or on the hulls of ships making transoceanic voyages hulls. In general, within anthropogenically-modified systems, these and many other exotics may have an advantage over natives (Dafforn et al. 2009, Johnston et al. 2009), as natives are now existing in conditions different than those in which they have evolved. This has been called the "selection regime alteration" hypothesis, where exotics are in essence "preadapted" to conditions in recipient environments (Byers 2002).

It is likely that observed patterns also arose from higher-order processes representing more than the sum of individual responses to copper. Community assembly in this study began on bare substrate, representing conditions that would be encountered during early successional stages, such as after a space-clearing disturbance or on a cleaned boat hull. Thus space, a resource which influences invasion patterns in more well-developed communities (see Stachowicz et al. 1999; Davis et al. 2000), was initially not limiting and was equally available to native and exotic species. It has often been observed that non-native species are relatively successful during these early stages of community development (Lozon and MacIsaac 1997). Factors such as the timing and duration of pollutant exposure can affect invader domination of aquatic communities during their assembly (Piola and Johnston 2008). Our results further demonstrate that the degree of early invader success is related to the degree of environmental degradation. Given this predisposition of exotics to occupy bare space, however, the relative success of invaders may decrease with time. For example, significant declines in abundance and richness of exotic plants have been found over time in old fields (Meiners et al. 2002). Although we predict that continued environmental degradation would promote exotics over longer time periods as well, additional studies would be necessary to confirm this.

The effort to characterize ecosystem vulnerability to invasions is of both theoretical and practical importance, providing insight into the basic structure and function of ecological communities as well as into potential management actions that address the growing threat of species invasions. Our results, as well as others in marine environments (Piola and Johnston 2008), demonstrate that polluted marine habitats can favor invaders, independent of propagule pressure. When considered in the context of past findings addressing physical disturbance in terrestrial systems, it suggests that invaders may be facilitated by habitat degradation irrespective of differences in invader supply. Under natural conditions, however, decreased habitat quality and supply of potential invaders often will not be isolated. Indeed, vector strength and conditions that promote invasibility often conspire to increase invader success. Areas that are vulnerable to invasion due to anthropogenic activities, such as urbanized lands or waters, also tend to have abundant sources of potential invaders due to the strength and diversity of vectors. Although this confluence of species movement and ecosystem vulnerability is a sure recipe for invasions, we suggest that current efforts to institute effective vector management should be more tightly coupled with efforts to improve environmental conditions in order to minimize invader success within ecosystems.

Acknowledgments We thank the staff at the Romberg Tiburon Center and Smithsonian Environmental Research Center, as well as Brian Steves, Emma Crooks, and Kerstin Wasson for helping with this research. This research was funded by the Maryland Sea Grant Program (R/IS-10).

Open Access This article is distributed under the terms of the Creative Commons Attribution Noncommercial License which permits any noncommercial use, distribution, and reproduction in any medium, provided the original author(s) and source are credited.

\section{Appendix 1: Reanalysis with assignment of 5 cryptogenic species to the exotic category}

In order to address the possible effects of cryptogenic species, we redid some analyses with different categorizations. Of the cryptogenic species, 5 were considered probable exotics, and for this analyses were moved from the cryptogenic to exotic category. This resulted in 19 exotic, 16 native, and 9 cryptogenic species. Analyses with these groupings yielded results quite similar to those with the more conservative assignment of exotic status. For total species per treatment, exotics did not significantly decrease with increasing copper (slope $=0.002 \pm 0.006$; $P=0.76$ ), while natives did (slope $=-0.033 \pm$ $0.006 ; P=0.01)$. There were significant differences in the slopes of the lines $(P=0.006)$. For average 
Table 4 (A) Average numbers of native and exotic species on the treatment and control plates. Analyses were done on logtransformed data, and data presented are back-transformed averages as well as lower and upper limits representing one SE about the mean. (B) Randomized Complete Block ANOVA tables for exotic and native species responses to copper

\begin{tabular}{|c|c|c|c|c|c|c|}
\hline \multirow[t]{2}{*}{ (A) Treatment } & \multicolumn{3}{|c|}{ Native species } & \multicolumn{3}{|c|}{ Exotic species } \\
\hline & \multicolumn{3}{|c|}{ Mean (SE range) } & \multicolumn{3}{|c|}{ Mean (SE range) } \\
\hline Control & \multicolumn{3}{|c|}{$8.7(8.1-9.3)$} & \multicolumn{3}{|c|}{$6.8(6.0-7.7)$} \\
\hline $0 \mu \mathrm{g} / 1$ & \multicolumn{3}{|c|}{$10.1(9.5-10.8)$} & \multicolumn{3}{|c|}{$7.6(7.0-8.1)$} \\
\hline $15 \mu \mathrm{g} / 1$ & \multicolumn{3}{|c|}{$9.0(8.0-10.1)$} & \multicolumn{3}{|c|}{$8.2(7.3-9.2)$} \\
\hline $50 \mu \mathrm{g} / 1$ & \multicolumn{3}{|c|}{$9.2(8.0-10.7)$} & \multicolumn{3}{|c|}{$6.8(5.9-7.8)$} \\
\hline $100 \mu \mathrm{g} / \mathrm{l}$ & \multicolumn{3}{|c|}{$7.3(6.3-8.4)$} & \multicolumn{3}{|c|}{$8.5(7.7-9.3)$} \\
\hline $200 \mu \mathrm{g} / 1$ & \multicolumn{3}{|c|}{$6.0(5.2-6.8)$} & \multicolumn{3}{|c|}{$5.2(3.4-7.9)$} \\
\hline \multirow[b]{2}{*}{ (B) Source of variation } & \multicolumn{3}{|c|}{ Native species } & \multicolumn{3}{|c|}{ Exotic species } \\
\hline & df & $F$ & $P$-value & df & $F$ & $P$-value \\
\hline Treatment & 5 & 4.43 & 0.007 & 5 & 0.87 & 0.516 \\
\hline Block & 4 & 4.91 & 0.006 & 4 & 1.85 & 0.159 \\
\hline Error & 20 & & & 20 & & \\
\hline
\end{tabular}

See text for more detail

species richness per plate, ANOVA's revealed no significant differences across treatments for exotics, while differences remained significant for natives (see Appendix Table 4).

\section{References}

Blair RB (1996) Land use and avian species diversity along an urban gradient. Ecol Appl 6:506-519

Burke MJW, Grime JP (1996) An experimental study of plant community invasibility. Ecology 77:776-790

Byers JE (2002) Impact of non-indigenous species on natives enhanced by anthropogenic alteration of selection regimes. Oikos 97:449-458

Carlton JT (1979) History, biogeography, and ecology of the introduced marine and estuarine invertebrates of the Pacific coast of North America. Ph.D Thesis. University of California, Davis

Carlton JT (1996) Biological invasions and cryptogenic species. Ecology 77:1653-1655

Chytrý M, Jarošík V, Pyšek P, Hájek O, Knollová I, Tichý L, Danihelka J (2008) Separating habitat invasibility by alien plants from the actual level of invasion. Ecology 89:15411553

Clark GF, Johnston EL (2005) Manipulating larval supply in the field: a controlled study of marine invasibility. Mar Ecol Prog Ser 289:9-19

Clarke KR, Gorley RN (2001) PRIMER v5: User Manual/ Tutorial. PRIMER-E Ltd., Plymouth

Clarke KR, Warwick RM (2001) Change in marine communities: an approach to statistical analysis and interpretation. PRIMER-E Ltd, Plymouth
Cohen AN, Carlton JT (1995) Nonindigenous aquatic species in a United States estuary: a case study of the biological invasions of the San Francisco Bay and Delta. U.S. Fish and Wildlife Service and National Sea Grant College Program (Connecticut Sea Grant)

Colautti RI, Grigorovich IA, MacIsaac HJ (2006) Propagule pressure: a null model for biological invasions. Biol Invasions 8:1023-1037

Connell JH (1978) Diversity in tropical rain forests and coral reefs. Science 199:1302-1310

Crooks JA, Suarez A (2006) Hyperconnectivity, invasive species, and the global breakdown of natural barriers to dispersal. In: Crooks KR, Sanjayan MA (eds) Connectivity conservation: Maintaining connections for nature. Cambridge University Press, Cambridge, pp 451-578

Crooks KR, Suarez AV, Bolger DT (2004) Avian assemblages along a gradient of urbanization in a highly fragmented landscape. Biol Conserv 115:451-462

D'Antonio CM, Dudley TL, Mack M (1999) Disturbance and biological invasions: direct effects and feedbacks. In: Walker L (ed) Ecosystems of disturbed grounds. Elsevier, Amsterdam, pp 413-451

Dafforn KA, Glasby TM, Johnston EL (2009) Links between estuarine condition and spatial distributions of marine invaders. Divers Distrib 15:807-821

Davies KF, Chesson P, Harrison S, Inouye BD, Melbourne BA, Rice KJ (2005) Spatial heterogeneity explains the scale dependence of the native-exotic diversity relationship. Ecology 86:1602-1610

Davis MA, Grime JP, Thomson K (2000) Fluctuating resources in plant communities: a general theory of invasibility. J Ecol 86:1602-1610

Elton CS (1958) The ecology of invasions by animals and plants. Wiley, New York 
Fine PVA (2002) The invasibility of tropical forests by exotic plants. J Trop Ecol 18:687-705

Floerl O, Pool TK, Inglis GJ (2004) Positive interactions between nonindigenous species facilitate transport by human vectors. Ecol Appl 14:1724-1736

Foster BL, Smith VH, Dickson TL, Hildebrand T (2002) Invasibility and compositional stability in a grassland community: relationships to diversity and extrinsic factors. Oikos 99:300-307

Gelbard JL, Belnap J (2003) Roads as conduits for exotic plant invasions in a semiarid landscape. Conserv Biol 17: 420-432

Grime JP (1973) Competitive exclusion in herbaceous vegetation. Nature 242:344-347

Hobbs RJ, Atkins L (1988) Effect of disturbance and nutrient addition on native and introduced annuals in plant communities in the Western Australia wheatbelt. Aust J Ecol 13:171-179

Hobbs RJ, Huenneke LF (1992) Disturbance, diversity, and invasion: implications for conservation. Conserv Biol 6:324-337

Johnston EL, Piola RF, Clark GF (2009) The role of propagule pressure in invasion success. In: Rilov G, Crooks JA (eds) Biological invasions of marine ecosystems: ecological, management and geographic perspectives. Springer, Heidelberg, pp 133-151

Knight KS, Reich PB (2005) Opposite relationships between invasibility and native species richness at patch versus landscape scales. Oikos 109:81-88

Kowarik I (1995) On the role of alien species in urban flora and vegetation. In: Pyšek P, Prach K, Rejmánek M, Wade M (eds) Plant invasions-General aspects and special problems. SPB Academic Publishing, Amsterdam, pp 85-103

Levine JM, D'Antonio CM (1999) Elton revisited: a review of evidence linking diversity and invasibility. Oikos 87: $15-26$

Levine JM, D'Antonio CM (2003) Forecasting biological invasions with increasing international trade. Conserv Biol 17:322-326

Lockwood JL, Cassey P, Blackburn T (2005) The role of propagule pressure in explaining species invasions. Trends Ecol Evol 20:223-228

Lohrer AM, Chiaroni LD, Hewitt JE, Thrush SF (2008) Biogenic disturbance determines invasion success in a subtidal soft-sediment system. Ecology 89:1299-1307

Lonsdale WM (1999) Global patterns of plant invasions and the concept of invasibility. Ecology 80:1522-1536

Lozon J, MacIsaac H (1997) Biological invasions: are they dependent on disturbance? Environ Rev 5:131-144

Mead R (1988) The design of experiments. Cambridge University Press, Cambridge

Meiners SJ, Pickett STA, Cadenasso ML (2002) Exotic plant invasions over 40 years of old field successions: community patterns and associations. Ecography 25:215-223

Menke SB, Holway DA (2006) Abiotic factors control invasion by Argentine ants at the community scale. J Anim Ecol 75:368-376

Olyarnik SV, Bracken MES, Byrnes JE, Hughes AR, Hultgren KM, Stachowicz JJ (2009) Ecological factors affecting community invasibility. In: Rilov G, Crooks JA (eds) Biological invasions of marine ecosystems: ecological, management, and geographic perspectives. Springer, Heidelberg, pp 587-617

Petryna L, Moora M, Nunes CO, Cantero JJ, Zobel M (2002) Are invaders disturbance limited? Conservation of mountain grasslands in Central Argentina. Appl Veg Sci 5:195-202

Piola RF, Johnston EL (2006a) Differential resistance to extended copper exposure in four introduced bryozoans. Mar Ecol Prog Ser 311:103-114

Piola RF, Johnston EL (2006b) Differential tolerance to metals among populations of the introduced bryozoan Bugula neritina. Mar Biol 148:997-1010

Piola RF, Johnston EL (2008) Pollution reduces native diversity and increases invader dominance in marine hardsubstrate communities. Divers Distrib 14:329-342

Piola RF, Johnston EL (2009) Comparing differential tolerance of native and non-indigenous marine specis to metal pollution using novel assay techniques. Environ Pollut 157:2853-2864

Preisler RK, Wasson K, Wolff W, Tyrrell MC (2009) Invasions of estuaries versus the adjacent open coast: a global perspective. In: Rilov G, Crooks JA (eds) Biological invasions in marine ecosystems. Ecological, management, and geographic perspectives. Springer, Heidelbderg

Ruiz GM, Fofonoff PW, Carlton JT, Wonham MJ, Hines AH (2000) Invasion of coastal marine communities in North America: apparent patterns, processes, and biases. Annu Rev Ecol Syst 31:481-531

Sax DF, Brown JH (2000) The paradox of invasion. Glob Ecol Biogeogr 9:363-371

Shea K, Chesson P (2002) Community ecology theory as a framework for biological invasions. Trends Ecol Evol $17: 170-176$

Stachowicz JJ, Whitlatch RB, Osman RW (1999) Species diversity and invasion resistance in a marine ecosystem. Science 286:1577-1579

Stachowicz JJ, Fried H, Osman RW, Whitlatch RB (2002) Biodiversity, invasion resistance, and marine ecosystem function: reconciling pattern and process. Ecology 83:2575-2590

Suarez AV, Bolger DT, Case TJ (1998) Effects of fragmentation and invasion on native ant communities in coastal southern California. Ecology 79:2041-2056

Torchin ME, Lafferty KD, Dobson AP, McKenzie WJ, Kuris AM (2003) Introduced species and their missing parasites. Nature 421:628-630

Tyser RW, Worley CA (1992) Alien flora in grasslands along road and trail corridors in Glacier National Park, USA. Conserv Biol 6:253-262

Veltman CJ, Nee S, Crawley M (1996) Correlates of introduction success in exotic New Zealand birds. Am Nat 147:542-557

Von Holle B (2005) Biotic resistance to invader establishment of a southern Appalachian plant community is determined by environmental conditions. J Ecol 93:16-26

Woitke M, Dietz H (2002) Shifts in dominance of native and invasive plants in experimental vegetation. Perspect Plant Ecol Syst Evol 5:165-184 